九州大学学術情報リポジトリ

Kyushu University Institutional Repository

\title{
Design Review Based on Failure Mode to visualise reliability problems in the development stage of mechanical products
}

Shimizu, Hirokazu

Toyota Motors

Otsuka, Yuichi

Department of Mechanical Engineering Science, Kyushu University

Noguchi, Hiroshi

Faculty of Engineering, Kyushu University

http://hdl. handle. net/2324/26064

出版情報: International Journal of Vehicle Design. 53 (3)，pp.149-165，2010-07. Inderscience バージョン:

権利関係: (C) 2010 Inderscience Enterprises Ltd. 


\title{
Design Review Based on Failure Mode to Visualize Reliability Problems in the Development Stage of Mechanical Products
}

\section{Hirokazu Shimizu}

Toyota Motors,

1, Toyota-cho, Toyota,

Aichi 471-8572, Japan

E-mail: hirokazu_shimizu@mail.toyota.co.jp

Yuichi Otsuka

Department of Mechanical Engineering Science,

Kyushu University,

744 Moto-oka, Nishi-ku, Fukuoka-shi, Fukuoka 819-0395, Japan

E-mail: otsuka@vos.nagaokaut.ac.jp

\section{Hiroshi Noguchi*}

Faculty of Engineering,

Kyushu University,

744 Moto-oka, Nishi-ku,

Fukuoka-shi, Fukuoka 819-0395, Japan

Fax: 81-92-802-0001

E-mail:nogu@mech.kyushu-u.ac.jp

${ }^{*}$ Corresponding author

\begin{abstract}
The concept of Mizen-Boushi (reliability problem prevention) has been applied to automotive development. A quality innovation process " $G D^{3}$ ", which means "Good Design", "Good Discussion" and "Good Design Review ", has recently been developed. Authors planned to utilize a System Design Review during development, in which we discuss potential failure modes, root causes and examine parts drawing and prototype parts designs using the DRBFM (Design Review Based on Failure Mode) method. This paper will introduce the specific framework of the System DRBFM as a universal Mizen-Boushi method, which can be utilized for the discussions of a complex system to parts or elements with hierarchy block diagrams of product and management. Case study of the System DRBFM for development of the Electric Power Steering system(EPS) is demonstrated, which visualizes details of practices and possible concerns by participants. System DRBFM can then previously visualize latent problems in hierarchical structure of design products in the development stage.
\end{abstract}

Keywords: Reliability, System, System Management, Management Engineering, FTA, FMEA, GD ${ }^{3}$, System DRBFM, Creativity.

Reference to this paper should be made as follows: Shimizu, H., Otsuka, Y. and Noguchi, H. (2010) 'Design review based on failure mode to visualise reliability problems in the development stage of mechanical products', Int. J. Vehicle Design , Vol. 53, No. 3, pp.149-165. 
Biographical notes: Hirokazu Shimizu received his $\mathrm{PhD}$ in Mechanical Engineering at the Kyushu University in Japan. He is a Senior Engineer at Toyota Motors. His research interests include proactive prevention methods in design processes and robust design.

Yuichi Otsuka is a Post Doctoral fellow at the Kyushu University, Japan. He received his $\mathrm{PhD}$ in Engineering at the Kyushu University. His research interests are safety system, safety management and theory of complexity.

Hiroshi Noguchi is a Professor of Faculty of Engineering, Kyushu University. He received his Doctor of Engineering at Kyushu University. His research interests are strength of materials, applied physics and safety system.

\section{Introduction}

A number of accidents have been recently reported that resulted from poor reliability of technology and quality management. The subsequent problem is that these reported accidents are considered avoidable, in which the causes are already known and it was possible to take countermeasures. In other words, if these causes are found in the design stage, almost all of the accidents could be prevented. Therefore, it is important to find the way of problem finding in the design stage to prevent avoidable accidents.

Once a problem occurs by a manufacturer, damage by the problem causes not only a financial loss, but also a reduced reliability and brand image for the maker. It is extremely difficult to restore the poor reliability and image. Also, in the automobile manufactur- 
ing industry, each maker has taken much effort to manufacture more reliable product in a shorter development period, in response to the rapid request by the market. To achieve this purpose, each designer should prevent in advance(=Mizen-Bousi) possible problems in the short term. If designers' errors cannot be found in the design stage, they result in enormous loss such as recalls and damage lawsuits.

There are various approaches in order to effectively find latent problems in a design stage. Wright (Wright, 1997) reviewed the process of managing engineering changes in a product. He argued that effective process of visualizing the effect flow by the engineering changes through a design process is much important to analyze their effect of product's quality. Tavcar and Duhovnik (Tavcar, 2005)discussed the contents of checklist for the purpose of evaluating the efficacy of engineering change management in one organization. Their list do not include the details of estimating potential errors in the changes. Lee et al.(Lee, 2005) simulated the delay in a schedule by errors in engineering changes on the assumed error rates, which is helpful in scheduling constructive project. Lee et al. (Lee, 2006)developed CECM(Collaborative environment for Engineering Change Management). The system is web-based database archiving related documents to engineering changes. They also considered the ontology model of automobile product, which is helpful for designers to search similar cases as a current case he considers. Eckert(Eckert, 2006)discussed the various methodology to visualize risks involved in engineering changes; risk matrix, cascade model of effect propagation by changes and Component connection network. They pointed out the critical path if risk by the engineering changes should be visualized by using the discussed methods in order to secure the reliability of the considering products.

On the other hand, Huang investigated the Hong Kong industrial company for its situation of using engineering change management system(Huang, 1998, 2003). Though ISO guideline of engineering change management has already published, the company only introduced paper based system using their original forms, which has difficulty in searching a specific related document to concern potential errors in a current change. Huang also developed a web-based design review system (Huang, 2001, 2002, 2004) to discuss effects of engineering changes, which is helpful to preserving the detailed contents of the reviews. Peng and Trappey (Peng, 1998)proposed a data model of a product compatible to ISO. Bouikni also developed a design review system based on the concept of Product Features Evolution Validation Model(PFEV)(Bouikni, 2006) to discuss the effect of changes in design stage. However, they discussed little in defining engineering changes and in finding errors involved in the changes through a design review process. Moreover, it is little considered that the method of using the data of engineering changes is important to determine a proactive solution to risks from the changes themselves or the errors involved in design review process. Once a product including engineering changes has released, the product should become a reliable product model in service if no troubles occurred after the release. When designers develop a new product, they define from the engineering changes on the basis of the past reliable product design. If an organization fails to update the reliable product model, the designers must check risks in engineering changes with no standard and it probably suffers both reliability of products and efficiency of product design. It is indispensable to prepare the contents about past reliable data and checklist (reliability test for the considered possible failures) in order to allow designers to concentrate on considering the new risk from current changes.

The authors proposed DRBFM(Design review Based on Failure Mode)(Shimizu and Yoshimura, 2004) framework to meet the above needs. At first, definition of Good De- 


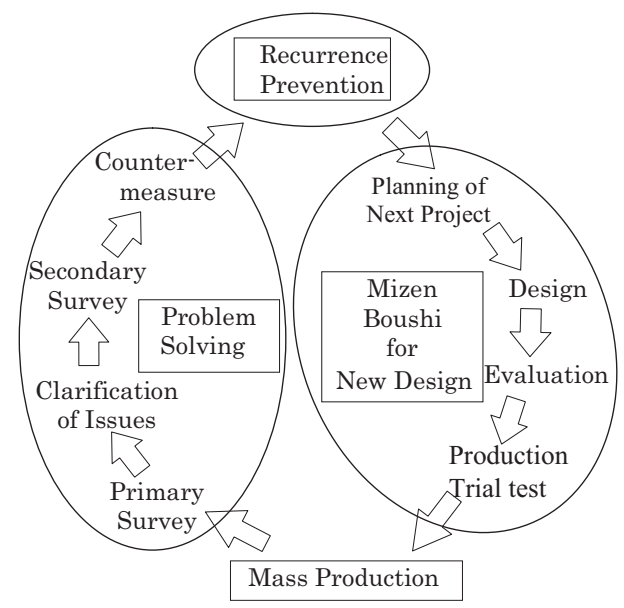

Figure 1 Mizen-Bousi cycle for the basic concept of the management system to prevent reliability problems in the design stage

sign(Gd:design features-function), which means the reliable products data in past service, is necessary to specify a sufficiently reliable design conditions of a product. However, designers need to change some conditions from GD, because they should develop new model to satisfy consumer's needs. In this case, engineering changes involves the following two styles;intentional changes in product design features and incidental changes in service environment. Comparing the changes with GD allows the designers to concern possible failures by the changes. After the prediction, the review process is conducted to check whether all possible failures are considered and errors in the solutions for them exist. After the DRBFM process, the data of the developed model is added in the contents of GD. This framework can be effective in continuous design change management in the automobile company.

In the previous report, we pointed out the necessity of a problem solving process of proactive prevention that includes finding latent problems in design drawings, taking specific measures to correct them and improving the design ideas(Shimizu and Yoshimura, 2004; Shimizu and Noguchi, 2003). This paper proposes the advanced DRBFM process for considering the entire structure of the developing product. We firstly discuss the basic concept of proactive prevention $G D^{3}$. The procedure of advanced DRBFM, called System DRBFM, is then presented. A case study of the System DRBFM for the Electric Power steering System (EPS) certifies the validity and effectiveness of our proposal.

\section{Problem solving, recurrence prevention and proactive prevention (Mizen-Bousi)}

Figure 1 shows the management cycle of problem finding and prevention that involves problem solving, recurrence prevention and proactive prevention (Mizen-Bousi). The necessity of proactive prevention has recently been emphasized to improve product reliability. However, the difference between the contents of recurrence prevention with those of proactive prevention has only been slightly discussed. The proactive prevention cycle is composed of the three main parts. 
Problem solving To take technical measures for the observed problems.

Recurrence prevention To establish a design management system for preventing recurrence of the noted technical problems.

Proactive prevention (Mizen-Bousi) To find latent problems in a new design or design change.

The main task in the problem solving stage is to find the technical causes of the specific problems. If a past considered failure list and solutions for them (contents of reliability checklist) are prepared, designers is able to make a solution for them routinely. Otherwise it loads for the designers to predict failures and its causes by themselves.

The task in the recurrence prevention stage needs to involve the establishment of a design management system for prevention rather than a high technical solution. To establish the recurrence prevention system, the organization must arrange the design standards, reference system for past troubles and design procedure including the utilization of these tools.

On the other hand, it is necessary for designers to have the ability of problem finding, which means that they can predict and notice possible problems in the proactive prevention stage. Exactly the same problem as those in the past rarely occurs. The designers should then predict a similar problem such that their causes are already known but the problem itself has not previously occurred. The aspect of proactive prevention is subsequently different from those in the stages of problem solving and recurrence prevention as already mentioned (Yoshimura, 2003).

To accomplish proactive prevention, it is indispensable for the designers to reminisce about past reliable designs of the products, which are used in practical service for a certain period. However, the designers cannot resemble exactly the same design as in the past when they are engaged in new products or design changes. Therefore, it is necessary to prepare a specific procedure for the design review process to stimulate the creativity of designers to help finding the latent problems. The design review process probably includes a reference to past reliable designs, consideration for the changes from those designs and finding possible problems by comparing the differences. In considering the hierarchical structure of the new product;system-sub system-components-parts, the structure contains the parts or components or sub-systems that possesses the almost same functions as those in the past design. Designers can define engineering changes in appropriate level of product's structure by considering the hierarchical structure of past design. Subsequently they analyze risks in the changes and errors in solutions for them, in order to take sufficient measures for the changes from GD, which judges whether the conditions of the new product model containing engineering changes can be regarded as the GD(a past reliable design in a practical service condition).

\section{$3 G D^{3}$; Basic concept of proactive prevention}

Failure Mode and Effects Analysis (FMEA)(Stewart and Melchers, 1996) and Fault Tree Analysis (FTA) (Stewart and Melchers, 1996) have been typically utilized in a design review to prevent reliability problems. However, the results of these methods are not always connected to practice measures that the designers can understand what to execute or evaluate. The reason for these interruptions is that the contents of the measures are often too abstract to allow designers to consider specific changes in the design or the evaluation. 
Therefore, formal practice of FMEA, which has lost their contents, becomes less effective in considering reliability of the product design.

The authors then introduced the $G D^{3}$ concept(Yoshimura, 2002) toward the basic management concept of problem finding in the design review stage. The $G D^{3}$ concept includes three main parts.

Good Design To specify the design conditions of a reliable product that is used in practical service for a certain term and to keep these conditions for another design.

Good Discussion To discuss and find latent problems by the difference in current design from the Good Design. Because designers cannot avoid deviating from the Good Design in the case of a design change or new design to achieve new requests by the market. Designers should then notice the deviation and find the problems caused by the changes using the discussion with the necessary expertise.

Good Design Review Specific process for design review including problem finding and determining countermeasures for it.

With this concept, designers can note the safe condition of the designs and find their latent problems in the design change. We have developed the Design Review Based on Failure Mode (DRBFM)(Shimizu and Yoshimura, 2004) to arrange the design review procedure according to the $G D^{3}$ concept.

\section{Design Review Based on Failure Mode}

The execution procedure for proactive prevention in the design stage must include the process of visualization for the structure and phenomena, problem finding using the visualized phenomena and problem solving for finding the possible failure causes. However, the procedure using conventional methods such as FMEA and FTA is not specified and also depends on the participants' experience. This is because these procedures are not focused on finding the problems and obviously involves its procedure. On the other hand, our proposed process is obviously based on the $G D^{3}$ concept for proactive prevention(Yoshimura, 2002). Furthermore, its procedure includes the problem finding process from intentional changes (Shimizu and Yoshimura, 2004)(design change by the designers) and incidental changes (Shimizu and Yoshimura, 2004)(the changes in the service environment not caused by the designers). For this aspect, our procedure possess a valid effectiveness for problem finding rather than those of conventional processes(Shimizu and Noguchi, 2003). Details of DRBFM procedure are then discussed as follows.

Figure 2 shows the columns from DRBFM work sheet. Each column is filled according to the sequential finishing of each stage. In the beginning, the structure of the designing product and its functions of each element are specified by the drawings and tables. Next, the intentional and incidental changes are presented by the designer. Each participant compares the changes from the "Good Design" condition and predicts possible failures due to the changes. Furthermore, the technical causes of possible failures are analyzed according to a brain storming discussion. Finally, measures to design, manufacture and evaluate of all of the considered technical causes are determined. This process can be the typical process of actualizing the formal knowledge from the potential or tacit knowledge of the participants ' subjectivity. Furthermore, the entire discussion is aimed at stimulating the participant's creativity(Simozyo, 2003; Ichikawa, 2003; Shiba, 2003) for helping with the problem solving. 

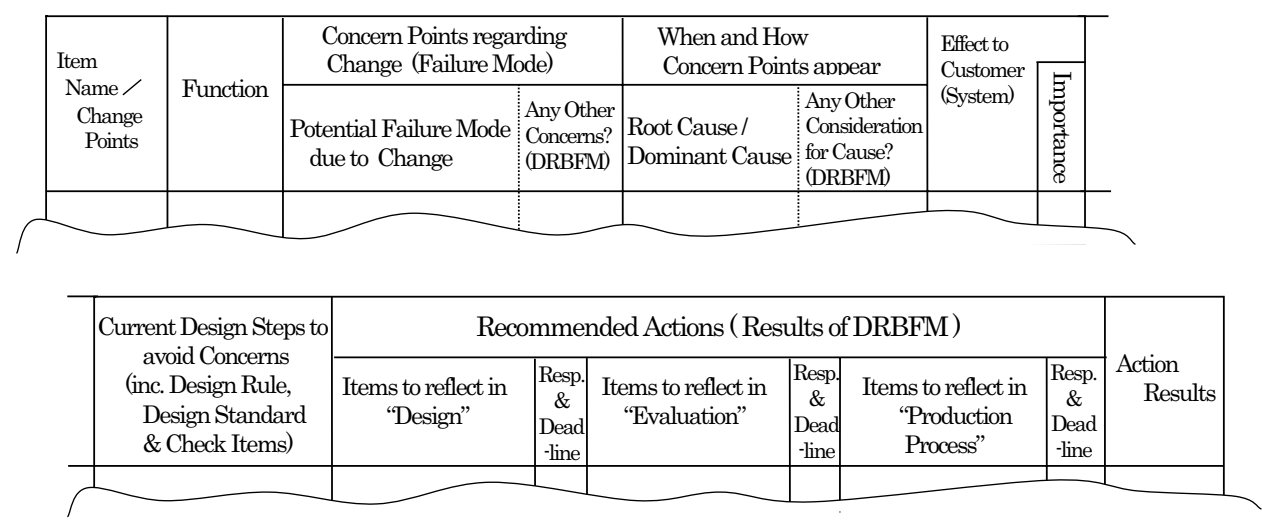

Figure 2 Columns in DRBFM worksheet

[Phase1]

Hierarchical block diagram
[Phase2]

Defining changes
[Phase3]

Implementing DRBFM

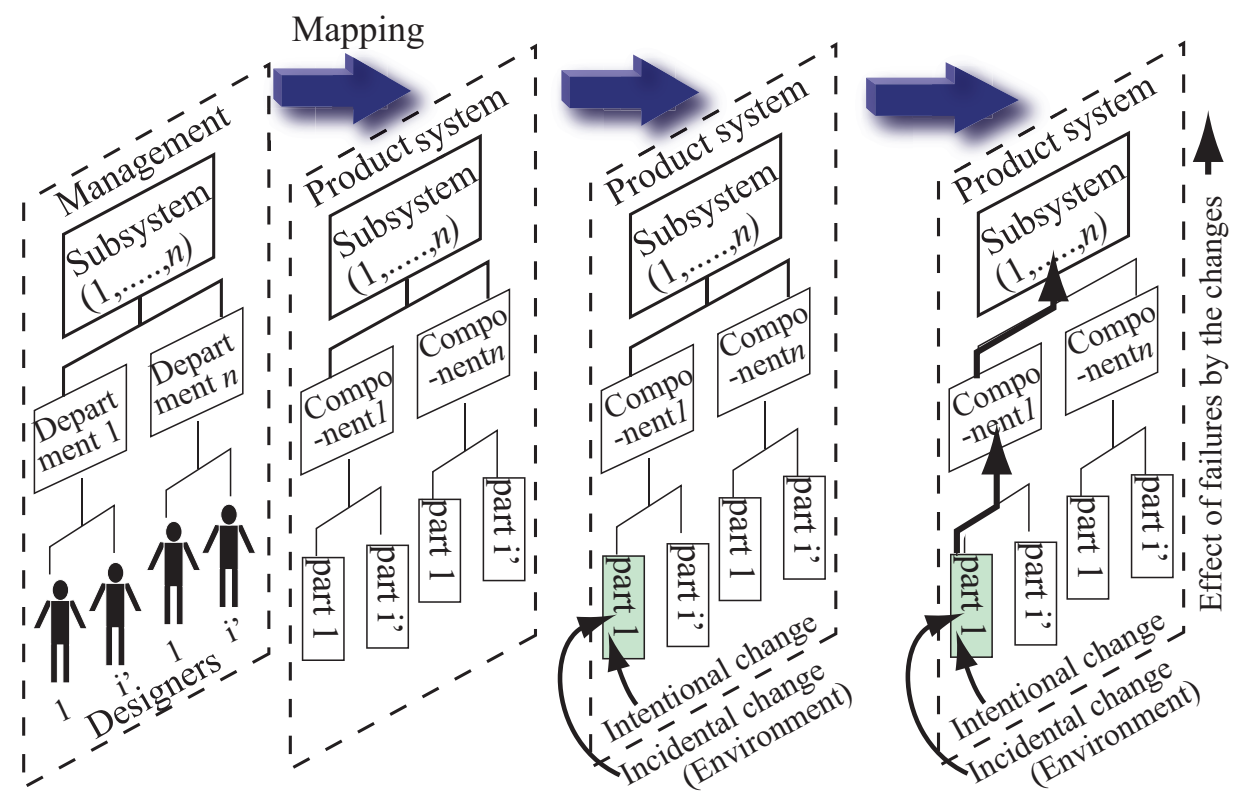

Figure 3 Entire procedure of system DRBFM process

\section{System DRBFM}

The system is composed of a hierarchical set of components in order to achieve the requested function(Von Bertalanffy, 1968). The system involves complex interactions among the components and the components between classes. To develop a comprehensive proactive prevention procedure that considers the entire hierarchical structure from the element of a product to whole system, its consideration process must be specified in DRBFM pro- 

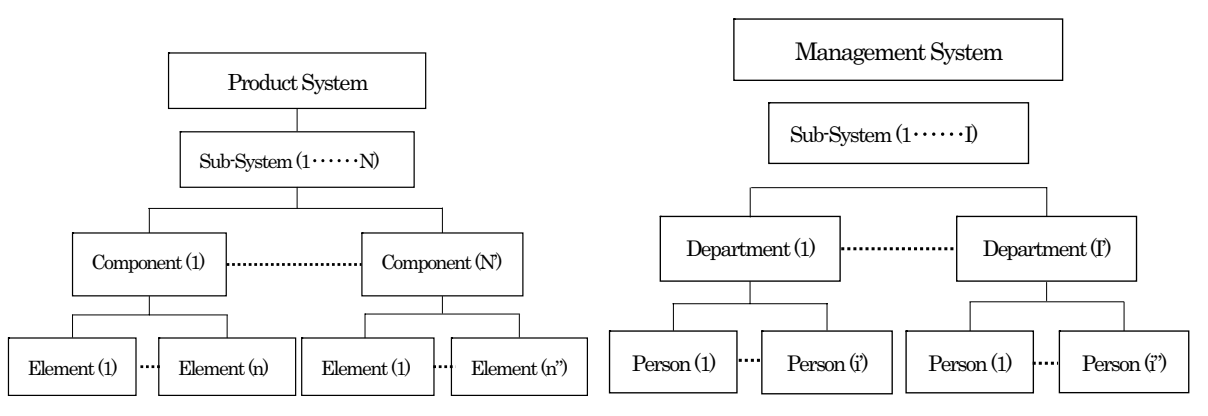

Figure 4 Hierarchical block diagram of Figure 5 Management structure of design product structure corresponding to the charge of the product structure

cess. We then improved the DRBFM process to the System DRBFM, which considers entire structure of products in practical use.

In the another report(Shimizu and Yoshimura, 2004), the authors developed the DRBFM process according to the product development flow. We then improved the process in order to consider the hierarchical structure of the products. The whole procedure of the System DRBFM process is shown in Figure 3. The utilization tools in the System DRBFM include the hierarchical structure map of the products, the intentional and incidental changes table and the DRBFM work sheet. If necessary, a fault tree diagram is added in order to analyze the cause of specific failure. The details of each process in Figure 3 are shown in the next sections.

\subsection{Phase 1: Determining the participant and hierarchical structure of the product}

In the beginning, the hierarchical structure of the product must be determined in Figure 4. Many of the incidents due to the insufficient communication between sections or persons have been reported(Von Bertalanffy, 2001; Hatamura, 1996). Therefore, it should be noticed that the function of connection among the sections and persons are considered to prevent insufficient communication, as shown in Figure 5. In the automobile industry, an electric control to achieve various kinds of design requests has recently been utilized. It is then important to consider what expertise, such as parts' functions, manufacturing, software development and design maker, are necessary for the System DRBFM. Once the necessary expertise has been determined, participants including designer, expert reviewer and authorized professional adviser who possess excellent experience and techniques for the specific product are easily selected.

If a failure of selecting the expertise occurs, the result of the System DRBFM significantly suffers. To prevent this failure, it is indispensable to specifically determine the hierarchical structure of the system in Figure 4. The hierarchical structure of the system that includes the system, sub-system, components and elements are determined using the parts tables by the designer. Furthermore, charges for each block in Figure 4 should correspond to that in Figure 5. This is because the reviewer for the specific components or element will be easily selected by the relationship between Figure 4 and Figure 5 . 
Table 1 Sample of modified point list involving intentional and incidental changes in a part

\begin{tabular}{|c|c|c|c|c|}
\hline \multicolumn{3}{|c|}{ Modified Item } & New Design & $\begin{array}{l}\text { Current } \\
\text { Design }\end{array}$ \\
\hline \multirow[t]{2}{*}{ Part Name } & $\begin{array}{l}\text { Intentional } \\
\text { Change }\end{array}$ & $\begin{array}{c}\text { Material } \\
\text { Surface Treatment (Paint \& Plating) } \\
\text { Structure \& Shape } \\
\text { Production \& Distribution } \\
\text { (change into overseas plant from domestic) }\end{array}$ & & \\
\hline & $\begin{array}{l}\text { Incidental } \\
\text { Change }\end{array}$ & $\begin{array}{c}\text { Environmental Condition } \\
\text { (Stress,Temperature....etc.) }\end{array}$ & & \\
\hline
\end{tabular}

\subsection{Phase 2: Determining the intentional and incidental changes in design}

Once the hierarchical structure of the product is determined, the targets for the review that involve differences from the "good design" are then visualized. In the system development, the number of targets for review often becomes immense due to the number of parts and elements. To decrease the unnoticed problem of the target to be reviewed, it is important to determine that the targets for review are limited to the changes from the reliable design in advance. The determination of the target will help the designer and reviewer of the System DRBFM to notice what aspect needs to be discussed.

Table 1 shows a sample of the modified item list that includes the intentional and incidental changes in a part. For example, intentional changes involve changes in the material selection, surface treatment, structural shape and production (distributing) place. Incidental changes also include environmental changes in manufacturing or service. All of the changes must be visualized in the form of Table 1 . If some changes are hidden in the brain of the designer, it causes the unnoticed problem of a latent problem due to the hidden changes. With Table 1, the designer and participant consider whether or not, the changes results in some failure. This certification process should be executed by all participants to be reviewed by various experts.

\subsection{Phase 3: DRBFM for problem finding and solving}

With the hierarchical structure in Figure 4, possible problems due to the changes in the products are discussed. In more detail, the system, sub-system, component and element are the hierarchy in Figure 4. In each class, possible failure (we call this the "concerns") from changes and its effect on the connection between parts are considered. If some concerns can occur in the considered points, adaptive measures for these must be determined by the designer and professional advisor. All of the considered concerns and its measures are listed in the DRBFM worksheet. A specific example will be shown in the later section.

For the design review of the hierarchical system, participants have difficulty in determining the target of discussion in many parts of Figure 4. We can easily determine the target in the discussion using DRBFM procedure. Because in the DRBFM procedure, the safety condition of the design can be previously determined as the "Good design" and the targets of discussion are also noticed as the changes from the safe condition. This concept can help the participant in the DRBFM to notice what failures (concerns) occur. The DRBFM procedure then enables the participant to stimulate their creativity and find the concerns. Once the concerns are found, taking the associated measures easy. Because the 


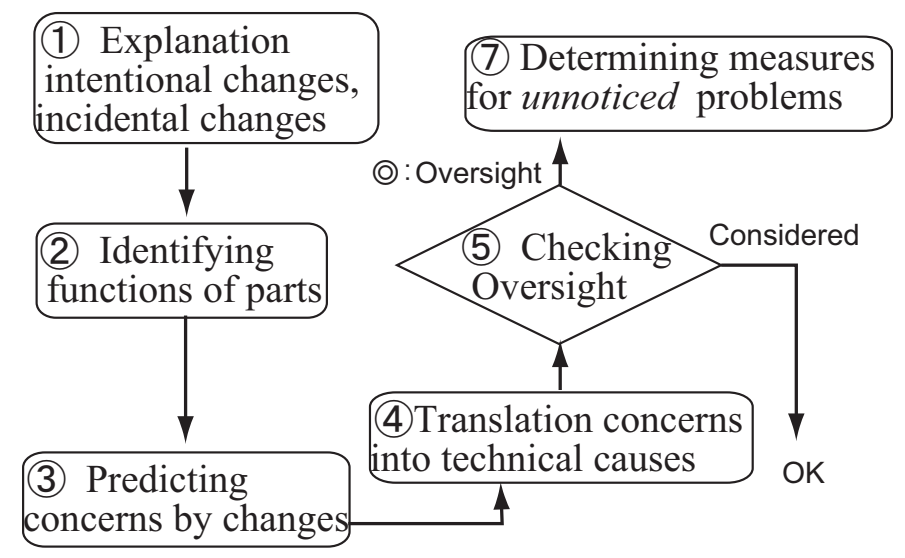

Figure 6 Phase 3; Discussion procedure of finding problems and considering solutions for all of them.

cause of the concerns is already-known and past measures for them are also known.

The procedure according to Figure 6 yields the possible failures by the changes.

1.Explaining the contents of the changes by the designer The designer in charge of part 1 in Figure 3 explains the contents of the changes to the participants.

2.Determining the function of the target part The designer determines a specific function of the target. Other participants examine the contents of the determined function.

3.Predicting concerns by the changes The designer considers the concerns by the changes, which possibly damages the function. The contents of concerns are filled in the DRBFM sheet(the form shown in Figure 2). If the designer consider no concern due to one change, this should be validated by the discussion among the participants.

4.Detailed consideration for the technical cause of the concerns If necessary, Fault Tree Analysis is practiced, whose top phenomenon is the current concern. The branch of the fault tree grows as long as the contents of the cause at the tip node in the tree possesses a sufficient specificity, which are validated by the participants.

5.Inspection of an unnoticed point All participants determine whether any unnoticed point was lost in the consideration by using the DRBFM worksheet;Discussing the failures from changes with past failure style data and considering each node from top concerns in fault trees.

6.Determining measures for all causes by the concerns The designer checks whether the all causes from the concerns are treated by specific measures. 

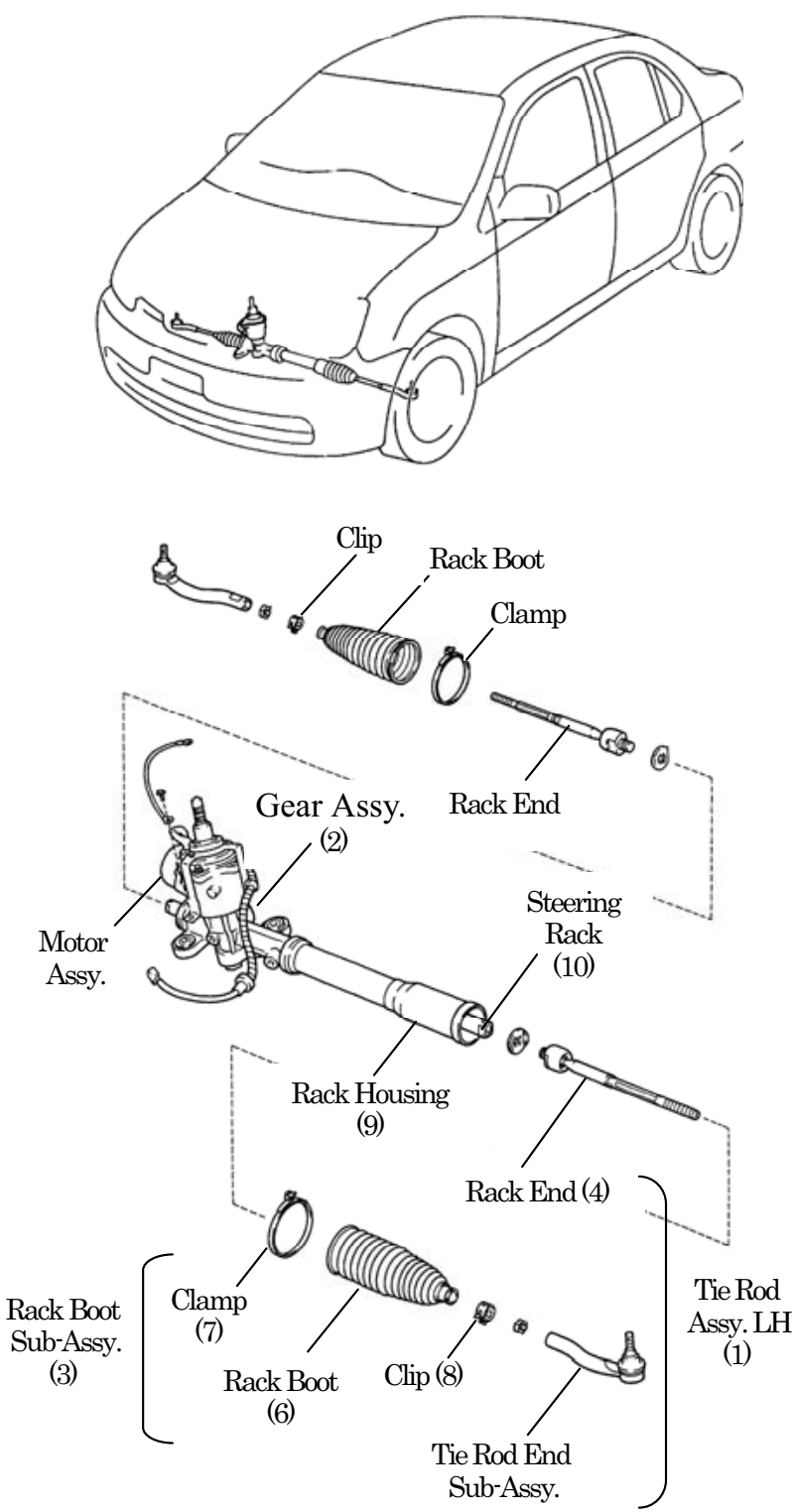

Figure 7 Target of System DRBFM; Electric Power Steering system (EPS)

\section{Case study of system DRBFM}

\subsection{Phase 1: Hierarchical structure of electric power steering system (EPS)}

We conducted the System DRBFM process for the development of the Electric Power Steering system(EPS) shown in Figure 7. The EPS is composed of both a mechanical system and an electric control system. The participants should then involve both expertises. It is impossible for the participants to understand the interrelations in the structure without 
Table 2 Modified Item List for Rack Boot and Clamp of EPS

\begin{tabular}{|c|c|c|c|}
\hline \multicolumn{2}{|c|}{ Modified Item } & New Design & Current Design \\
\hline \multirow{5}{*}{ 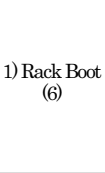 } & Material & Thermoplastic Elastomer (TPO) & Chloroprene Rubber (CR) \\
\hline & Surface Treatment & (Same) & - \\
\hline & Structure \& Shape & $\mathrm{t}=0.5 \sim 1.5$ & $\mathrm{t}=1.6$ \\
\hline & Production \& Distribution & Blow Molding & Compression Molding \\
\hline & Environmental Condition & (Same) & - \\
\hline \multirow{3}{*}{ 2) $\underset{(7)}{\text { Clamp }}$} & Material & SUS 430MT & SUS 430 \\
\hline & Surface Treatment & (Same) & - \\
\hline & Structure \& Shape & & \\
\hline
\end{tabular}

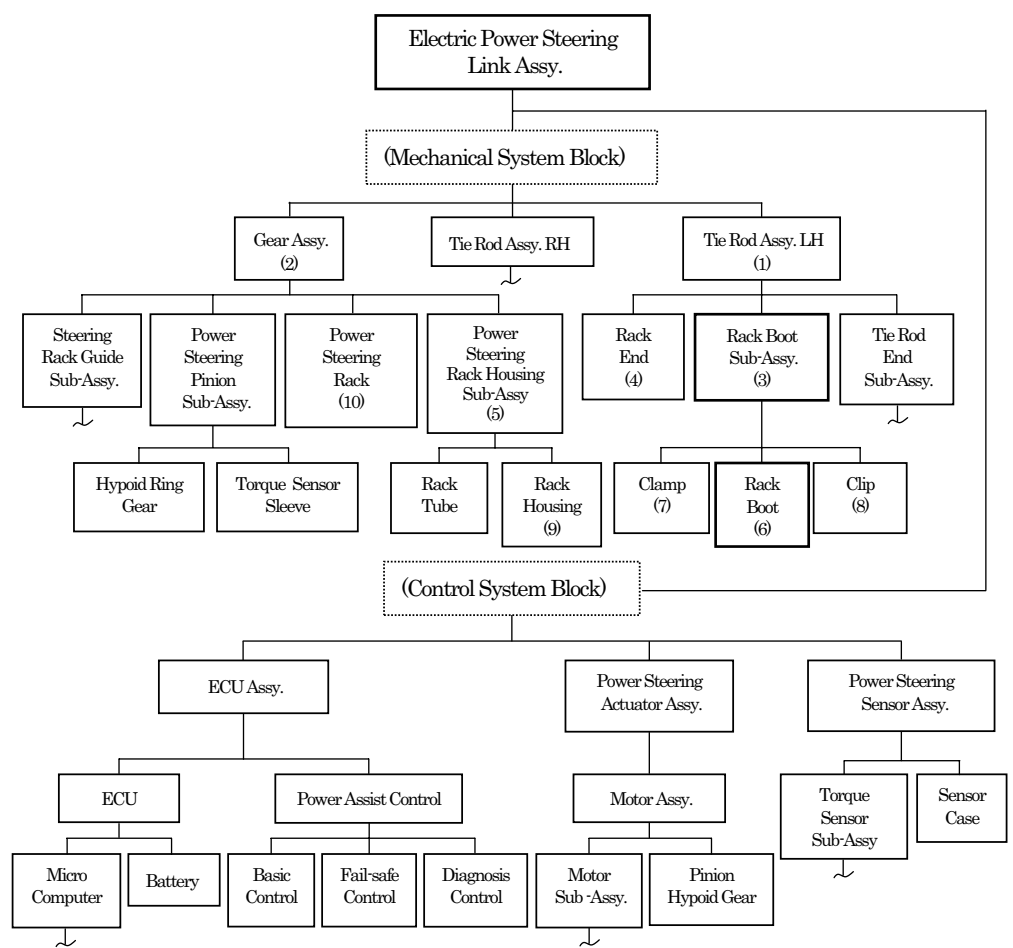

Figure 8 System Hierarchy Block Diagram of Electric Power Steering system (EPS)

Figure 7. Figure 7 can visualize the complex structures of both systems and the interactions between components. In this figure, some connection from part to tiny elements is omitted by the judgment of the designer and professional advisor. This is to decrease the load of the DRBFM for the elements that are judged to have a little effect on safety.

In the hierarchical structure, the material changes in the Rack Boot (6) (bold block in Figure 7) is the target of the DRBFM. Table 2 shows the list of changes in the Rack Boot (6). Details of the table will be discussed in later. According to the process in Figure 3, the participant can determine the target of the DRBFM from the changes in the Rack Boot (6). 


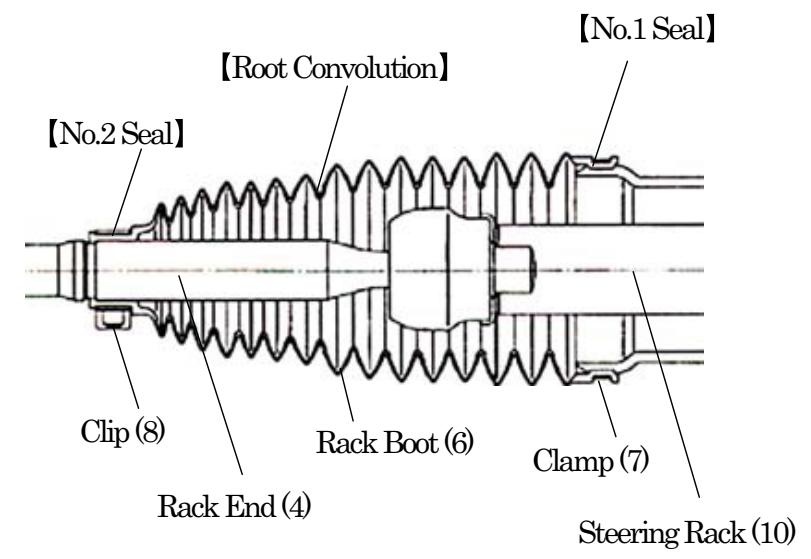

Figure 9 Rack Boot Sectional View

Table 3 Material Properties of Rack Boot

\begin{tabular}{|c|c|c|c|}
\hline & & $\begin{array}{l}\text { Thermo- } \\
\text { plastic } \\
\text { Elastomer }\end{array}$ & $\begin{array}{c}\text { Chloroprene } \\
\text { Rubber }\end{array}$ \\
\hline \multirow{3}{*}{$\begin{array}{c}\text { Dry } \\
\text { Condition }\end{array}$} & $\begin{array}{l}\text { Hardness } \\
(\mathrm{Hs})\end{array}$ & 95 & 50 \\
\hline & $\begin{array}{l}\text { Strength } \\
\text { (Mpa) }\end{array}$ & 20 & 15 \\
\hline & $\begin{array}{c}\text { Elongation } \\
(\%)\end{array}$ & 500 & 450 \\
\hline \multirow{2}{*}{$\begin{array}{l}\text { High } \\
\text { Temp. } \\
\text { Condition } \\
\left(100^{\circ} \mathrm{C}\right)\end{array}$} & $\begin{array}{l}\text { Modulus }\left(\mathrm{M}_{100}\right) \\
\text { Change }\end{array}$ & -50 & -10 \\
\hline & $\begin{array}{c}\text { Strength } \\
\text { Change after } \\
\text { 500hrs }(\%) \\
\end{array}$ & 0 & -35 \\
\hline \multicolumn{2}{|c|}{$\begin{array}{l}\text { Compression Set }(\%) \\
70^{\circ} \mathrm{C} \times 22 \mathrm{hrs}\end{array}$} & 40 & 10 \\
\hline \multicolumn{2}{|c|}{ Low Temp. Brittleness $\left({ }^{\circ} \mathrm{C}\right)$} & -60 & -40 \\
\hline \multicolumn{2}{|c|}{$\begin{array}{c}\text { PS Oil Resistance } \\
\text { Volume Change (\%) }\end{array}$} & +25 & +5 \\
\hline
\end{tabular}

Sub-system Interaction(Fitness) between Tie Rod Assy. (1) and Gear Assy. (2)

Component Rack Boot Sub-Assy. (3), Rack Boot Sub-Assy.(3), Rack End (4) in Tie Rod Assy. (1) and Rack Housing Sub-Assy. (5) in Gear Assy. (2).

Element Rack Boot (6), Clamp (7), Clip (8) in Rack Boot Sub-Assy.(3) and Rack Housing (9) in Rack Housing Sub-Assy. (5). 


\begin{tabular}{|c|c|c|c|c|c|c|c|c|c|c|}
\hline \multirow{2}{*}{$\begin{array}{l}\text { Item } \\
\text { name / } \\
\text { Change } \\
\text { points }\end{array}$} & \multirow[b]{2}{*}{ Function } & \multicolumn{2}{|c|}{\begin{tabular}{|l|}
$\begin{array}{l}\text { Concerns regarding } \\
\text { change (Failure mode) }\end{array}$ \\
\end{tabular}} & \multicolumn{2}{|c|}{$\begin{array}{l}\text { When and how } \\
\text { concern points appear }\end{array}$} & \multirow{2}{*}{$\begin{array}{l}\text { Effect to } \\
\text { customer } \\
\text { (System) }\end{array}$} & \multirow{2}{*}{\begin{tabular}{|l|} 
Current design \\
steps to avoid \\
concerns \\
(inc. design rule, \\
design standard \\
\& check items) \\
\end{tabular}} & \multicolumn{3}{|c|}{ Recommended actions (Results of DRBFM) } \\
\hline & & $\begin{array}{l}\text { Potential } \\
\text { failure mode } \\
\text { due to change } \\
\end{array}$ & (DRBFM) & $\begin{array}{l}\text { Root cause/ } \\
\begin{array}{l}\text { Dominant } \\
\text { cause }\end{array} \\
\end{array}$ & (DRBFM) & & & $\begin{array}{l}\text { Items to } \\
\text { reflect in } \\
\text { "Design" }\end{array}$ & $\begin{array}{c}\text { Items to } \\
\text { reflect in } \\
\text { "Evaluation" }\end{array}$ & $\begin{array}{l}\text { Items to } \\
\text { reflect in } \\
\text { "Production" }\end{array}$ \\
\hline \begin{tabular}{|c|} 
Rack boot \\
sub-assy \\
1.Rack Boot \\
1)Convolution \\
membrane \\
\end{tabular} & \begin{tabular}{|} 
Recipro- \\
cating \\
motion \\
\end{tabular} & $\begin{array}{c}\text { Recipro- } \\
\text { cating } \\
\text { resistance }\end{array}$ & & $\begin{array}{r}(* 1) \\
- \text { TPO hardnes } \\
\text { increased } \\
\\
\quad(50 \mathrm{Hs} \Rightarrow 9\end{array}$ & $\begin{array}{l}\text { ess } \\
\text { d } \\
95 \mathrm{Hs})\end{array}$ & $\begin{array}{c}\text { Poor } \\
\text { steering } \\
\text { feeling }\end{array}$ & & $\begin{array}{l}\text { Investigation } \\
\text { for increasing } \\
\text { resistance due } \\
\text { to hardness } \\
\text { change } \\
\end{array}$ & $\begin{array}{l}\text { Measuring } \\
\text { reciprocating } \\
\text { resistance }\end{array}$ & \\
\hline \multirow{3}{*}{$\mid \begin{array}{l}\text { 2) Root } \\
\text { convolution } \\
\text { [Modified } \\
\text { point } \\
\cdot \text { CR } \Rightarrow \text { TPO } \\
-\begin{array}{c}\text { Configu- } \\
\text { ration }\end{array}\end{array}$} & \multirow{3}{*}{$\begin{array}{l}\text { Protect } \\
\text { for } \\
\text { rack end }\end{array}$} & \multirow[b]{2}{*}{ Fracture } & & \multicolumn{2}{|c|}{$\begin{array}{l}\text { Cracking by flying } \\
\text { gravel }\end{array}$} & \multirow{3}{*}{$\begin{array}{l}\text { Steering } \\
\text { Operation } \\
\text { will not } \\
\text { work }\end{array}$} & $\begin{array}{l}\text { TPO material } \\
\text { advantage of high }\end{array}$ & mpact resistanœ) & $\begin{array}{l}\text { Glavelo meter } \\
\text { impact test } \\
\text { at }-40^{\circ} \mathrm{C}\end{array}$ & \\
\hline & & & & \multirow{2}{*}{\multicolumn{2}{|c|}{$\begin{array}{l}\text { - Bending fatigue cracking } \\
\text { at bellows section (PS oil, } \\
\text { high temp. \& heat age) } \\
\text { - Convolute deformation } \\
\text { due to heat or uneven } \\
\text { thickness (interference } \\
\text { with B/J) }\end{array}$}} & & $\begin{array}{l}\text { FEM analysis } \\
\text { (Max. strain } \\
\leqq \square \%)\end{array}$ & $\begin{array}{l}\text { Safety convolute } \\
\text { membrane ratio } \\
\geqq \square \%\end{array}$ & $\begin{array}{l}\text { Durability test } \\
\text { after heat age } \\
\left(100{ }^{\circ} \mathrm{C} \cdot 500 \mathrm{hrs}\right)\end{array}$ & \\
\hline & & Deformation & & & & & & $\begin{array}{l}\text { Addition ribs at } \\
\text { large \& small } \\
\text { convolute } \\
\text { sections }\end{array}$ & & $\begin{array}{l}\text { Thickness } \\
\text { Control } \\
\text { during blow } \\
\text { malding }\end{array}$ \\
\hline $\begin{array}{l}\text { 3) } \\
\text { No.1 Seal }\end{array}$ & Sealing & $\begin{array}{l}\text { Stress } \\
\text { relaxation }\end{array}$ & & \multicolumn{2}{|c|}{$\begin{array}{l}\text {-Stress relaxation } \\
\text { due to radiant heat } \\
\text { of exhaust pipe }\end{array}$} & \begin{tabular}{|l|l|}
$\begin{array}{l}\text { Steermng } \\
\text { operation } \\
\text { will not }\end{array}$ & $\mathrm{A}$ \\
\end{tabular} & $\begin{array}{l}\text { Uramping } \\
\text { at } \\
\text { plastic region }\end{array}$ & & \begin{tabular}{l|}
$\begin{array}{l}\text { Sealing test } \\
\text { after durability } \\
\text { test }\end{array}$ \\
\end{tabular} & $\begin{array}{l}\text { Ihickness } \\
\text { dimension } \\
\text { inspection }\end{array}$ \\
\hline & & Crack & & \multicolumn{2}{|c|}{$\begin{array}{l}\text { Cracking during } \\
\text { claming mmonome }\end{array}$} & due to. & & $\begin{array}{l}\text { Round shape } \\
\text { at clampend }\end{array}$ & & \\
\hline $\begin{array}{l}\text { 4) } \\
\text { No.2 Seal }\end{array}$ & Sealing & $\begin{array}{l}\text { Stress } \\
\text { relaxation }\end{array}$ & & & & & & & & \\
\hline \multicolumn{2}{|l|}{ 2.Clamp L } & & & & & \multicolumn{2}{|l|}{$\perp 1$} & & \multicolumn{2}{|c|}{$\perp$} \\
\hline \multicolumn{2}{|l|}{ 3.Clip I } & & & & & \multicolumn{2}{|c|}{11} & & \multicolumn{2}{|c|}{1} \\
\hline
\end{tabular}

Figure 10 DRBFM Worksheet of Rack Boot Sub-Assy.

The Rack Boot (6) includes the design changes in Table 2. The details of the Rack Boot (6) are shown in Figure 9. The participants determined the No.1, No.2 Seal section and Root Convolution section as the noticed target.

\subsection{Phase 2: Design changes in the rack boot}

Table 2 shows the design changes in the materials of the Rack Boot (6). The material was alternated from polychloroprene (CR) to a Thermo-plastic Olefine Elastomer(TPO). The contents of the changes are presented in Table 3. Compared with the current material, TPO has both merits and demerits in its characteristics.

Merit Strength change after heat aging(500hrs), Low temperature brittleness.

Demerit Modulus Change (M100), the changes in PS Oil resistance and Hardness.

The rest of the figure is the changes in the Compression set, which the designer previously considered countermeasures for its affect by adding the width of TPO. This comparison can visualize the possible problem by the changes to the participants. The participants then discuss the possible failure due to the demerit or other changes.

\subsection{Phase 3: DRBFM for rack boot}

Figure 10 shows the result of the DRBFM listed in the DRBFM worksheet. We now focus on the discussion to consider the Rack Boot (6) (mark*1). From Table 3, the hardness of the Rack Boot increases from $50 \mathrm{Hs}$ to $95 \mathrm{Hs}$. Participants noticed the problem of the increasing reciprocate resistance due to the change. This concern can result in the poor 
steering feeling. The participants then determined the measures for these concerns, such as the investigation for the increased resistance. Furthermore, these concerns are possibly connected to the problems in the Actuator Assy. or Power Assist Control in the control system. This point is related to the consideration of the newly targeted parts.

Using the same procedure, the consideration of other element, such as 2) the Root convolution, No.1 and No.2 seals were conducted. All of the results are listed in Figure 10. A similar consideration for another targets in the higher classes, such as the Rack End (4) in the Rod Assy. (1) and Rack Housing Sub-Assy. (5) in Gear Assy. (2), are also conducted using interactions in Figure 4 and the results in Figure 10. These results are listed in another worksheet to visualize the effects of concerns in the lower classes to the higher class.

The above procedure is the System DRBFM using a hierarchical structure in Figure 4, the intentional and incidental changes list (Tables 1 and 3) and DRBFM worksheet (Figure 10). The DRBFM procedures are conducted for considering the entire system to the element in the lowest class and also from the element to the entire system. This process can visualize the latent concerns in the interactions in the complex hierarchical structures and take specific measures for these using the necessary tools and appropriate expertise of the participants.

\section{Summary}

We developed the System DRBFM process based on the $G D^{3}$ concept (Good Design, Good Discussion, Good Design Review). The system DRBFM process, as a proactive prevention method in system development, can find the latent problem in the design ideas and take specific measures for the technical cause of these problems. Furthermore, the process is specified using the hierarchical structure diagram, modified lists and DRBFM worksheet. This point can help the reliability engineers to consider the way of introducing our proposed method to their workplace. We can now apply the concept to the safety management for patient safety(Otsuka and Noguchi, 2005), which is the application example in a very different field to certify the wide applicability of our concept.

Sadfsdfds. sadsadfsadfds

\section{References}

Wright, I. C., (1997) 'A review of research into engineering change management: Implications for product design', Design Studies, 18(1) pp.33-39.

Tav $\check{c}$ ar, J. and Duhovnik, J., (2005) 'Engineering change management in individual and mass production', Robotics and Computer-Integrated Manufacturing, 21(3) pp.205215.

Lee, S., Peña-Mora, F., and Park, M., (2005) 'Quality and change management model for large scale concurrent design and construction projects', Journal of Construction Engineering and Management, 131(8) pp.890-902.

Lee, H. J., Ahn, H. J., Kim, J. W., and Park, S. J., (2006) 'Capturing and reusing knowledge in engineering change management: A case of automobile development', Information Systems Frontiers, 8(5) pp.375-394. 
Eckert, C. M., Keller, R., Earl, C., and Clarkson, P. J., (2006) 'Supporting change processes in design: Complexity, prediction and reliability', Reliability Engineering and System Safety, 91(12) pp.1521-1534.

Huang, G. Q. and Mak, K. L., (1998) 'Computer aids for engineering change control', Journal of Materials Processing Technology, 76(1-3) pp.187-191.

Huang, G. Q., Yee, W. Y., and Mak, K. L., (2003) 'Current practice of engineering change management in Hong Kong manufacturing industries', Journal of Materials Processing Technology, 139(1-3 SPEC) pp.481-487.

Huang, G. Q., Yee, W. Y., and Mak, K. L., (2001) 'Development of a web-based system for engineering change management', Robotics and Computer-Integrated Manufacturing, 17(3) pp.255-267.

Huang, G. Q., (2002) 'Web-based support for collaborative product design review', Computers in Industry, 48(1) pp.71-88.

Huang, G. Q., Zhao, J. B., and Jiang, Z., (2004) 'Web-based design review portal with fuzzy set theoretic methods for fuel pump designs', International Journal of Computer Integrated Manufacturing, 17(3) pp.265-278.

Peng, T. . and Trappey, A. J. C., (1998) 'A step toward STEP-compatible engineering data management: The data models of product structure and engineering changes', Robotics and Computer-Integrated Manufacturing, 14(2) pp.89-109.

Bouikni, N., Desrochers, A., and Rivest, L., (2006) 'A product feature evolution validation model for engineering change management', Journal of Computing and Information Science in Engineering, 6(2) pp.188-195.

Shimizu, H., and Yoshimura, T., (2004) 'Reliability Problem Prevention Method of Stimulating Creativity and Visualizing Problems 1st report', Trans. Japan Soc. Mech. Eng. Series C, Vol.70 , No.689, pp.243-250.

Shimizu, H. , and Noguchi , H., (2003) 'Reliability Problem Prevention Method for Automotive Components' , Proc. of International Body Engineering Conference, JSAE , pp.371-376.

Yoshimura,T., (2000) 'Reliability Problem Solution, Recurrence Prevention and Precautionary Prevention; Looking from logistic curves', Quality Management(in Japanese), Vol.51, No.3, pp.266-270.

Yoshimura,Y., (2002) TOYOTA Precautionary Prevention TechniqueGD ${ }^{3}$ (in Japanese), JUSE Press., Tokyo.

Stewart, M.G., and Melchers, R.E., (1996) Probabilistic Risk Assessment of Engineering Systems, Chapman \& Hall, London.

Taylor, E., (1996) Subliminal Technology;Unlocking power of your own mind, Progressive Awareness Research, Medical Lake.

Bridger, R.S.,(2008) Introduction to Ergonomics, CrC PrI Llc, London. 
Shiba, S., Walden, D.,(2006) Break-through Management, Confederation of Indian Industry. India.

Von Bertalanffy, L., (1968) GENERAL SYSTEM THEORY, Foundations, Development, Applications, George Braziller, New York.

Kletz,T., (2001) Learning from Accidents Third Edition, Gulf Professional Publishing, London.

Reason, J., Hobbs, A., (2003) Managing Maintenance Errors : Practical Guide,Ashgate Publishing, London.

Otsuka, Y., and Noguchi, H., (2005) 'A Study on Managing Cycle of Measures for Incident based on Visualizing Problems', Proc. of ASME IMECE 05,Orlando, Florida, ASME, (CD-ROM), IMECE2005-80908. 